\title{
High-Performance Ultra-Compact Dual-Band Bandpass Filter for Global System for Mobile Communication-850/Global System for Mobile Communication-1900 Applications
}

\author{
Abbas Rezaei ${ }^{1}$ and Salah I. Yahya ${ }^{2,3}$ \\ ${ }^{1}$ Department of Electrical Engineering, Kermanshah University of Technology, \\ Kermanshah, Iran \\ ${ }^{2}$ Department of Software Engineering, Faculty of Engineering, Koya University, \\ Koya KOY45, Kurdistan Region - F.R. Iraq \\ ${ }^{3}$ Department of Communication and Computer Engineering, Cihan University-Erbil, \\ Erbil, Kurdistan Region - F.R. Iraq
}

\begin{abstract}
This work presents a novel microstrip dualband bandpass filter (BPF) using meandros spirals and patch cells, which is proposed for the $1^{\text {st }}$ time by this work. It occupies a very compact size of $0.0017 \lambda \mathrm{g}^{2}$. The proposed filter is designed to operate at $F_{01}=0.85 \mathrm{GHz}$ and $\mathrm{F}_{02}=1.85 \mathrm{GHz}$ for Global System for Mobile Communication (GSM)-850/ GSM-1900 applications. In addition to the small size, it has several advantages in terms of wide fractional bandwidths, low insertion losses, and high return losses at both channels. The simulated insertion losses at the lower and upper passbands are $0.05 \mathrm{~dB}$ and $0.1 \mathrm{~dB}$, respectively. Another advantage of the proposed BPF of this work is the attenuated harmonics, where it is able to suppress the $1^{\text {st }}, 2^{\text {nd }}, 3^{\text {rd }}$, and $4^{\text {th }}$ harmonics $\left(4.11 \mathrm{~F}_{01}\right)$ with $-20 \mathrm{~dB}$ maximum harmonic level.
\end{abstract}

Index Terms-Bandpass, Compact, Dual band, Filter, Global system for mobile communications, Microstrip.

\section{INTRODUCTION}

Due to having planar structures, microstrip filters are widely demanded by modern radiofrequency communication systems, especially small structures with high performance. With the development of multiband systems, dual-band bandpass filters (BPFs) are a must and commonly used. A well-designed microstrip filter must be compact with low loss and flat channels. Several structures have been utilized to obtain the microstrip dual-band BPFs (Hayati et al., 2012;

\section{ARO-The Scientific Journal of Koya University}

Volume VII, No.2 (2019), Article ID: ARO.10574, 4 pages

DOI: $10.14500 /$ aro. 10574

Received 20 October 2019; Accepted 27 November 2019

Regular research paper: Published 10 December 2019

Corresponding author's e-mail: a.rezaee@kut.ac.ir

Copyright (C) 2019 Abbas Rezaei and Salah I. Yahya. This is an open access article distributed under the Creative Commons Attribution License.
Murmu and Das, 2015; Avinash and Rao, 2017; Hasan et al., 2017; Rezaei and Noori, 2017; Khani et al., 2019; Sarkar and Moyra, 2019). However, all of them are very large with high insertion losses. A microstrip circular ring (Murmu and Das, 2015), star-shaped structure (Avinash and Rao, 2017), folded stepped-impedance resonator and an etched ground structure (Sarkar and Moyra, 2019), coupled open-loop resonators (Hasan et al., 2017; Hayati et al., 2012; Rezaei and Noori, 2017), and bended microstrip lines, rectangular resonators, and stepped-impedance resonator (Khani et al., 2019) have been utilized to design dual-band BPFs. Eun and Lee (2017) proposed a novel method for designing dualband BPF which consists of open-loop ring resonator and stepped-impedance resonator. Wen et al. (2018) designed a compact dual-band BPF using a pair of composite resonators. In Chen et al., 2018, novel dual-band BPF is proposed using a compact microstrip quint-mode multistub-loaded resonator. A high-performance filter must be able to attenuate the harmonics. Nevertheless, the proposed filters by Murmu and Das (2015), Avinash and Rao (2017), Sarkar and Moyra (2019), and Hayati et al. (2012) could not suppress the harmonics. Another important point of the filter design is creating flat passbands with low group delays (GDs). However, the designers Avinash and Rao (2017), Hasan et al. (2017); Khani et al., (2019); Hayati et al. (2012); Murmu and Das (2015); Rezaei and Noori (2017); and Sarkar and Moyra (2019) did not pay attention to this problem, whereas the reported filters by Sarkar and Moyra (2019); Hasan et al. (2017); Hayati et al. (2012); and Khani et al. (2019) have two narrow channels.

In this work, a microstrip dual-band BPF is proposed for global system for mobile communications (GSM), that is, GSM-850 and GSM-1900 (Personal Communications Service) which are used in most of North, South, and Central America. It is designed based on a novel compact structure. In comparison with the previous reported filters, our filter has 
the most compact size, the lowest insertion losses, and good return losses at both passbands. Meanwhile, it can attenuate the harmonics with a maximum harmonic level of $-20 \mathrm{~dB}$. Furthermore, the proposed dual-band BPF has two wide flat channels.

\section{Filter Design and Structure}

For designing a resonator, we need a structure with its $L C$ equivalent circuit. To miniaturize the size, the spiral cells with inductance features are a good option because they can save the size totally. We know that the large width microstrip cells have capacitance features. Moreover, patch cells are compact with capacitance properties. On the other hand, the coupling between microstrip cells provides small capacitors (named as coupling capacitors). Accordingly, a combination of coupled spirals attached to filled microstrip cells would be a good choice. As a result, we select our proposed resonator as presented in Fig. 1a. An approximated equivalent $L C$ model of the proposed resonator is presented in Fig. 1b, where the spiral cell is replaced by inductor $L_{\mathrm{s}}$ and patch feed lines are replaced by capacitors $C_{\mathrm{p}}$. In this approximated model, we ignored the effect of steps since they are considered only at the frequencies higher than $10 \mathrm{GHz}$.

Some information about the resonator behavior can be extracted from the $A B C D$ matrix. Therefore, at an angular frequency $\omega$, the $A B C D$ matrix of the proposed resonator is calculated as follows:

$$
T=\left[\begin{array}{ll}
A & B \\
C & D
\end{array}\right]=\left[\begin{array}{cc}
1 & \frac{2}{j \omega C_{p}}+j \omega L_{s} \\
0 & 1
\end{array}\right]
$$

To decrease the loss, a perfect impedance matching is needed. If the reflection coefficient $(\Gamma)$ becomes near zero, the matching will be improved. Therefore, the condition of perfect matching will be obtained as follows:

$$
\begin{aligned}
& \Gamma=\frac{A+B-C-D}{A+B+C+D}=0 \Rightarrow \\
& \frac{\frac{2}{j \omega \omega_{p}}+j \omega \omega_{s}}{\frac{2}{j \omega \omega_{p}}+j \omega \omega_{s}+2}=0 \Rightarrow \omega=\sqrt{\frac{2}{L_{s} C_{p}}}
\end{aligned}
$$

The perfect matching will be obtained at the angular resonance frequency $\omega$. This frequency can be tuned in accordance with Equation (2) easily. Therefore, the resonance frequency is flexible by changing the values of $L_{\mathrm{s}}$ and $C_{\mathrm{p}}$. From Equation (1), the input impedance of the proposed resonator is:

$$
\operatorname{Zin}=\frac{2-\omega^{2} C_{p} L_{s}}{j \omega \omega_{p}}
$$

Thus, it is a single-mode resonator with only a resonance frequency for $Z_{\text {in }}=0$. For a pre-determined angular resonance frequency of $\omega$, the proposed resonator can be miniaturized according to Equation (2) by choosing a small value for $L_{\mathrm{s}}$. Fig. 2 depicts the layout configuration of our filter with its corresponding dimensions in $\mathrm{mm}$. As shown in Fig. 2, the designed filter has a symmetric structure consisting of coupled spiral cells. To create additional capacitors, in some places, the width of the device is increased. When these capacitors are added to the inductors of the spiral structures, the passbands will be created.

\section{RESULTS AND DisCUSSION}

The simulation results are obtained by the electromagnetic simulator of advanced design system software. To extract the simulation results, a dielectric substrate of RT/Duroid 5880 with $\varepsilon_{\mathrm{r}}=2.2, h=31 \mathrm{mil}$, and $\tan \delta=0.0009$ is used. The proposed filter is well miniaturized with an overall size of $14.2 \mathrm{~mm} \times 7.7 \mathrm{~mm}=0.0017 \lambda \mathrm{g}^{2}$, where $\lambda \mathrm{g}$ is the guided wavelength calculated at $0.85 \mathrm{GHz}$. The simulated frequency response of the designed dualband BPF is depicted in Fig. 3a. The results show that the first passband is from $0.69 \mathrm{GHz}$ up to $1 \mathrm{GHz}$ with an operational center frequency of $\mathrm{F}_{\mathrm{o} 1}=0.85 \mathrm{GHz}$. The second resonance frequency is located at $\mathrm{F}_{\mathrm{o} 2}=1.85 \mathrm{GHz}$ with $-3 \mathrm{~dB}$ cutoff frequencies of $1.75 \mathrm{GHz}$ and $2 \mathrm{GHz}$. The introduced filter has two fractional bandwidths (FBWs) of $\mathrm{FBW} 1=36 \%$ and $\mathrm{FBW} 2=13.5 \%$ for the lower and upper passbands, respectively. The simulated insertion losses at the first and second passbands are $0.05 \mathrm{~dB}$ and $0.1 \mathrm{~dB}$, respectively, whereas at both passbands, the return losses
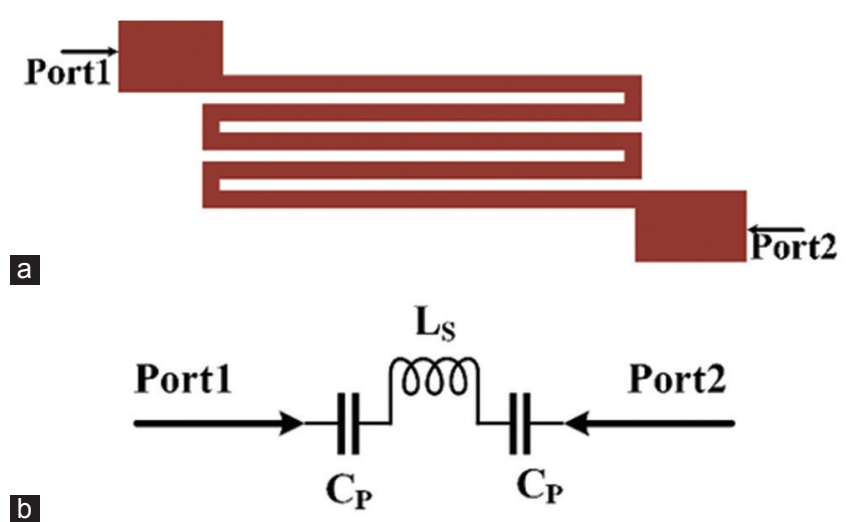

Fig. 1. Proposed resonator: (a) Layout, (b) approximated $L C$ model.

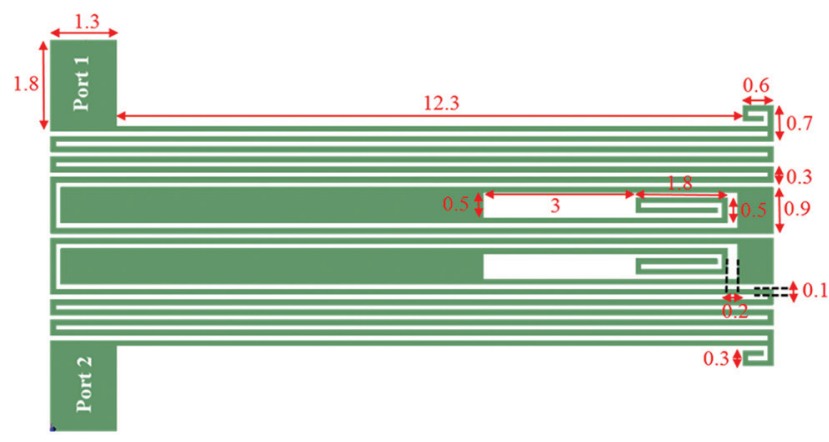

Fig. 2. Proposed bandpass filter. 

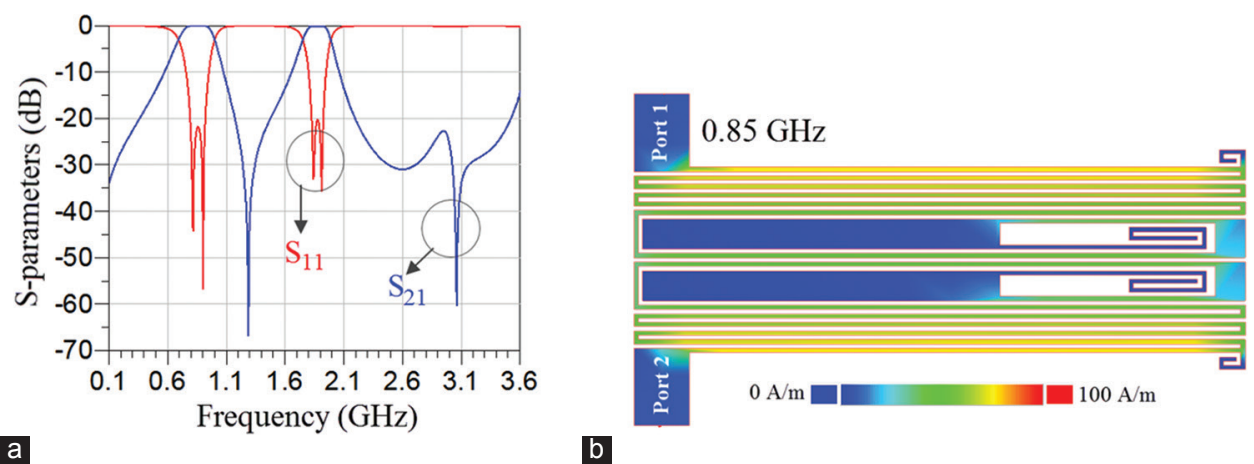

b
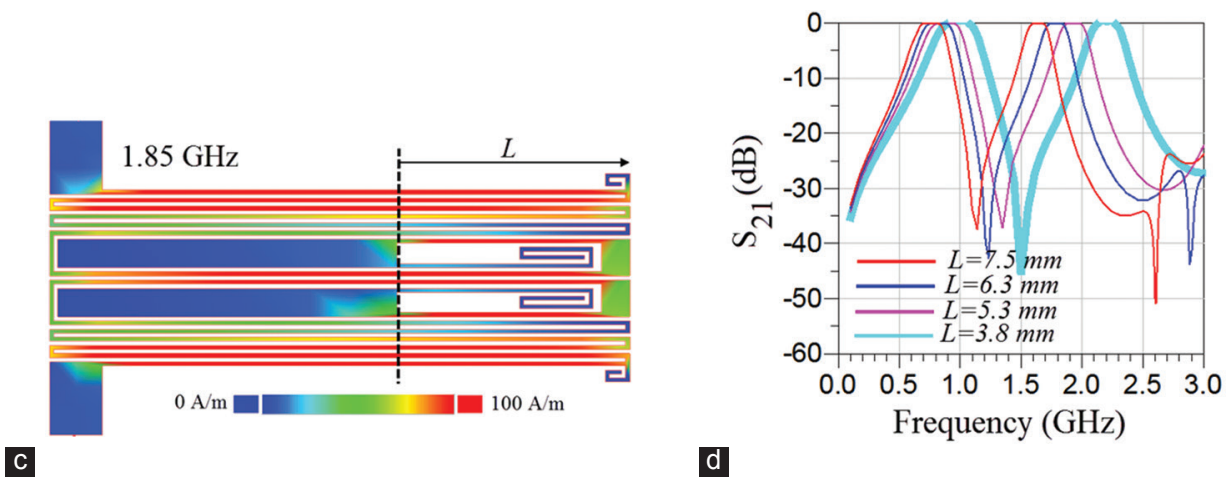

d

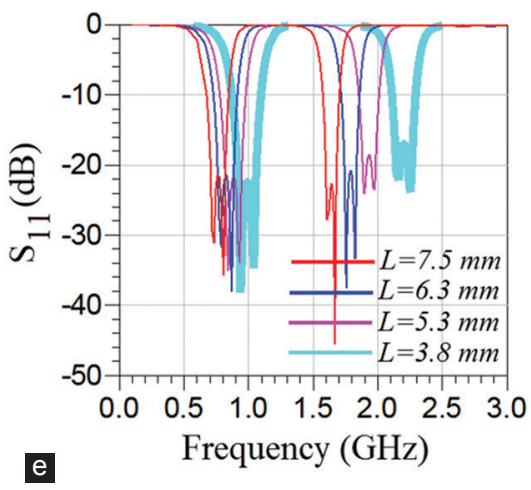

Fig. 3. (a) Frequency response of the designed dual-band bandpass filter, (b) Current density distribution at $0.85 \mathrm{GHz}$, (c) Current density distribution at $1.85 \mathrm{GHz}$, (d) $\mathrm{S}_{21}$ as a function of the physical length $L$, (e) $\mathrm{S}_{11}$ as a function of the physical length $L$.

TABLE I

Comparison Between This Work and Previous Dual-band Bandpass Filters ( $\mathrm{IL}_{1}$, $\mathrm{IL}_{2}$ : Insertion Losses at the Lower and Upper Passbands, RL ${ }_{1}$, $\mathrm{RL}_{2}$ : Return Losses at the Lower AND UpPer Passbands)

\begin{tabular}{|c|c|c|c|c|c|c|}
\hline References & $\overline{\mathrm{F}_{\mathrm{o} 1}, \mathrm{~F}_{\mathrm{o} 2}(\mathrm{GHz})}$ & $\mathrm{IL}_{1}, \mathrm{IL}_{2}(\mathrm{~dB})$ & $\mathrm{RL}_{1}, \mathrm{RL}_{2}(\mathrm{~dB})$ & FBW1\%, FBW2\% & Harmonic suppression & $\overline{\text { Size }\left(\lambda \mathrm{g}^{2}\right)}$ \\
\hline This work & $0.85,1.85$ & $0.05,0.1$ & $21.7,20$ & $36,13.5$ & Up to $1.89 \mathrm{~F}_{\mathrm{o} 2}$ & 0.0017 \\
\hline Murmu and Das,2015 & $2.38,5.2$ & $0.2,---$ & 19, --- & $44,15.3$ & No & --- \\
\hline Avinash and Rao, 2017 & $4.13,4.26$ & $1.78,1.97$ & 21,27 & $7.26,5.38$ & Up to $1.2 \mathrm{~F}_{\mathrm{o} 2}$ & --- \\
\hline Hasan et al., 2017 & $2.4,4.3$ & --- & --- & -- & $\mathrm{Up}$ to $2.5 \mathrm{~F}_{\mathrm{o} 2}$ & 0.096 \\
\hline Hayati et al., 2012 & $2.4,5.2$ & $0.53,0.59$ & $10,13.4$ & --- & Up to $1.7 \mathrm{~F}_{\mathrm{o} 2}$ & 0.037 \\
\hline Rezaei and Noori, 2017 & $2.39,5.7$ & $0.1,0.4$ & $21.3,16.6$ & $10.8,7.9$ & $\mathrm{Up}$ to $1.9 \mathrm{~F}_{\mathrm{o} 2}$ & 0.025 \\
\hline
\end{tabular}

FBW: Fractional bandwidth

are better than $20 \mathrm{~dB}$. The proposed filter can attenuate the harmonics from the second passband to $3.5 \mathrm{GHz}$ with -20 $\mathrm{dB}$ maximum harmonic level. Accordingly, it can suppress the harmonics up to $4.11 \mathrm{~F}_{\mathrm{o} 1}$ and $1.89 \mathrm{~F}_{\mathrm{o} 2}$. Fig. $3 \mathrm{~b}$ and $\mathrm{c}$ show the current density distribution of the proposed BPF at $0.85 \mathrm{GHz}$ and $1.85 \mathrm{GHz}$, respectively. As shown in these figures, the length $L$ is one of the most effective dimensions on the frequency response. The effect of physical length $L$ on the frequency response is presented in Fig. $3 \mathrm{~d}$ and e. As it can be seen, the resonance frequency is a function of the length $L$, whereby increasing the length $L$ both resonance frequencies shift to the left. 

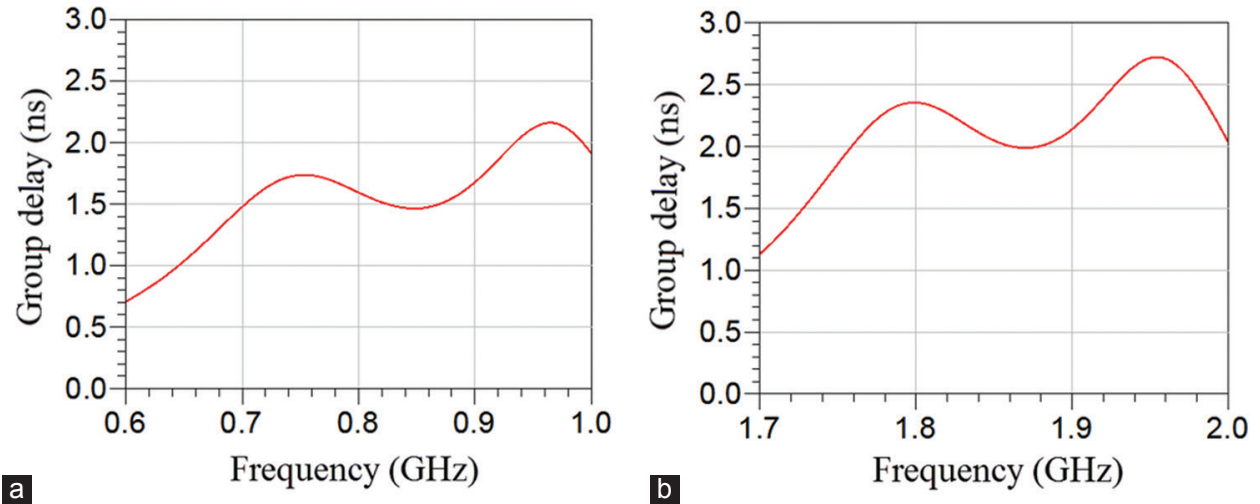

Fig. 4. Group delay of the designed dual-band bandpass filter at the (a) first passband, (b) second passband.

To show the advantages of this work, we compared the proposed BPF with the previous reported BPFs, as shown in Table I. As depicted in Table I, the lowest insertion losses and the most compact size are achieved by this work. On the other hand, in comparison with the previous works, the return losses, FBWs, and harmonic suppression are good. Only the proposed filter by Murmu and Das (2015) has wider bandwidths than the bandwidths of our proposed BPF. However, it could not attenuate harmonics.

The last important parameter in the filter design is the GD. A passband with high GD is subjected to time distortion. Despite this fact, the other reported filters mentioned in this work did not pay attention to this problem. The GD of the proposed filter at the lower and upper passbands is illustrated in Fig. 4a and b, respectively. As presented in these figures, the GDs at the first and second passbands are better than $2.2 \mathrm{~ns}$ and $2.7 \mathrm{~ns}$, respectively.

\section{CONCLUSION}

An ultra-compact microstrip dual-band BPF with an overall size of $0.0017 \lambda \mathrm{g}^{2}$ is designed in this work. The proposed filter is suitable for GSM applications. The proposed design is based on a novel structure consisting of coupled spiral cells. Our introduced filter has two FBWs of $36 \%$ and $13.5 \%$ with the return losses better than $20 \mathrm{~dB}$ at both passbands. The other advantages of this work are the suppressed harmonics and the lowest insertion losses at both passbands. Altogether with the comparison, results show that our proposed filter has a high performance, the most compact size, and a novel structure.

\section{REFERENCES}

Avinash, K.G., and Rao, I.S., 2017. Compact dual-mode microstrip bandpass filters with transmission zeros using modified star shaped resonator. Progress in Electromagnetics Research C, 71, pp.177-187.

Chen, C.F., Wang, G.Y., and Li, J.J., 2018. Compact microstrip dual-band bandpass filter and quad-channel diplexer based on quint-mode stub-loaded resonators. IET Microwaves, Antennas and Propagation, 12, pp.1913-1919.

Eun, J.W., and Lee, J.H., 2017. A microstrip dual-band bandpass filter using feed line with SIR. IEICE Electronics Express, 14, pp.1-8.

Hasan, M.F., Jalal, A.S., and Ahmed, E.S., 2017. Compact dual-band microstrip band pass filter design based on stub loaded resonator for wireless applications. In: Progress in Electromagnetics Research Symposium-Spring (PIERS). IEEE, St Petersburg, Russia, pp.22-25.

Hayati, M., Noori, L., and Adinehvand, A., 2012. Compact dual-band bandpass filter using open loop resonator for multimode WLANs. IET, Electronic Letters, 48, pp.573-574.

Khani, S., Danaie, M., and Rezaei, P., 2019. Miniaturized microstrip dual-band bandpass filter with wide upper stop-band bandwidth. Analog Integrated Circuits and Signal Processing, 98, pp.367-376.

Murmu, L., and Das, S., 2015. A dual-band bandpass filter for $2.4 \mathrm{GHz}$ bluetooth and $5.2 \mathrm{GHz}$ WLAN applications. Progress in Electromagnetics Research Letters, 53, pp.65-70.

Rezaei, A., and Noori, L., 2017. Tunable microstrip dual-band bandpass filter for WLAN applications. Turkish Journal of Electrical Engineering and Computer Sciences, 25, pp.1388-1393.

Sarkar, D., and Moyra, T., 2019. A compact and high selective microstrip dual-band bandpass filter. Progress in Advanced Computing and Intelligent Engineering, 713, pp.475-481.

Wen, P., Ma, Z., Liu, H., Zhu, Sh., Ren, B., Wang, X., and Ohira, M., 2018. A miniaturized dual-band bandpass filter using composite resonators with flexible frequency ratio. IEICE Electronics Express, 15(5), pp.1-6. 